\title{
Inhalt / Sommaire
}

Huldrych M.Koelbing, Heinrich Buess zum 70.Geburtstag (17.Mai 1981)

Hans Leonhard Küng, Heinrich Buess als Fabrikarzt.

Verzeichnis der Publikationen von Prof. Dr.med. Heinrich Buess 7

Heinrich Stamm, Die Entwicklung der Geburtshilfe in Basel 23

Huldrych M. Koelbing, «De conceptu et generatione hominis» - die lateinische
Fassung von Jakob Rueffs «Trostbüchle», Zürich 1554

Urs Boschung, Geburtshilfliche Lehrmodelle

Ulrich Tröhler, Klinisch-numerische Forschung in der brit. Geburtshilfe 1750-1820 69

Marie-Louise Portmann, Der Basler Stadtarzt Johannes Huber (1507-1571) 81

Friedrich Rintelen, Zur Geschichte der Basler Medizinischen Fakultät im ersten
Drittel dieses Jahrhunderts

Heinrich Schipperges, Der Arzt als Zeuge des Lebens $\quad 105$

René Bernoulli, Montaigne: ein Medizinprogramm im sechzehnten Jahrhundert $\quad 119$

Erwin H. Ackerknecht, Jüdische Ärzte als Gestalter der Weltmedizin 127

Luigi Belloni, Konsilien von Professoren aus Neapel und Padua gegen die Sehstörungen von G.V.Pinelli

Nikolaus Mani, J. J. Wepfers Doktordisputation über das Herzklopfen (1647)

Marta Meyer-Salzmann, Zur medizinischen Versorgung der Berner Landschaft im 18. Jahrhundert

Barbara C.Hansch-Mock, Arbeitshygiene in schweizerischen Kalendern des 19. Jahrhunderts

Loris Premuda, Arthur Menzel (1844-1878), einer der liebsten und tüchtigsten
Signter Schüler und der treuesten Freunde Billroths, Primarchirurg in Triest

Hans H. Walser, Ist das Wohl des Landesherrn in Wein zu trinken? 207

Werner Sackmann, Ein Beitrag zur Biographie, insbesondere der letzten Lebensjahre, von Emil Abderhalden (1877-1950)

Isaac Benguigui, La théorie de l'électricité de Nollet et son application en médecine à travers sa correspondance inédite avec Jallabert

René Renggli, Die Anfänge der Spirometrie im 19. Jahrhundert $\quad 247$

Hanno Beck, Carl Ritter - Christ und Geograph $\quad 259$

Buchbesprechungen

José Maria López Piñero, Ciencia y Technica en la Sociedad Española de los Siglos XVI y XVII (Erwin H. Ackerknecht)

R. J. Chr. V.ter Laage, J. A. W. Moleschott, 1822-1893 (Erwin H. Ackerknecht)

Georg August Goldfuss, Über die Entwicklungsstufen des Thieres - Omne vivum ex ovo (Hans-Konrad Schmutz)

Volume Commemorating the 75th Anniversary of G. A.Lindeboom (Heinz Balmer)

Walter Birchler, Die Augenanatomie des Fabricius ab Aquapendente (1537-1619) (Friedrich Rintelen) 